\title{
MULTI-OBJECTIVE DECISION MAKING FOR Z COORDINATOR AND OVERCUT IN $\mu$ - EDM PROCESS USING TUNGSTEN CARBIDE ELECTRODE FOR MACHINING OF TITANIUM ALLOY
}

\begin{abstract}
Research on optimization of technological parameters in micro-EDM is very important, and especially results in multi-objective optimization problem. It led to improve machining performance like machining accuracy, reduced electrode wear and improved surface quality. Recent studies mainly refer to the quality indicators of machining productivity and electrode wear, besides that machining accuracy and surface quality are also very important indicators but published results about them is very limited. In this study, Z Co-Ordinate $(\mathrm{Z})$ and overcut (OC) in micro-EDM using tungsten carbide (WC) electrode for Ti-6Al-4V were decided simultaneously by TOPSIS. Technological parameters which include Voltage (V), Capacitance (C) and Response surface methodology (RSM) were investigated in the presented research work. The results showed that the quality parameters $\mathrm{Z}$ and OC at optimal conditions were significantly improved. The surface quality behind the microEDM is also analyzed and evaluated, and it is good.
\end{abstract}

Nomenclature:

\begin{tabular}{|l|l|}
\hline V: Voltage & $\begin{array}{l}\text { MOORA: Multi-Objective Optimization Method by } \\
\text { Ratio Analysis }\end{array}$ \\
\hline C: Capacitance & PCA: Principal component analysis \\
\hline RPM: spindle rotation speed & SR: Surface roughness \\
\hline EDM: Electrical discharge machining & TWR: Tool wear rate \\
\hline WEDM: Wire electrical discharge machining & MRR: Material removal rate \\
\hline RSM: Response surface methodology & HV: Micro- hardness \\
\hline GRA: Gray relational analysis & EWR: Electrode wear ratio \\
\hline S/N: Signal-to-noise ratio & OC: Overcut \\
\hline GA: Genetic algorithm & TA: Taper angle \\
\hline $\begin{array}{l}\text { TOPSIS: Technique for order preference by similarity } \\
\text { to ideal solution }\end{array}$ & Z: Z Co-Ordinate \\
\hline AHP: Analytic hierarchy process method & SEM: scanning electron microscopy (SEM) \\
\hline NSGA-II: Nondominated sorting genetic algorithm & XRD: X ray diffraction \\
\hline
\end{tabular}

\footnotetext{
${ }^{1}$ Hanoi University of Industry, No. 298, CauDien Street, Bac TuLiem District, Hanoi, Vietnam, Faculty of Mechanical Engineering, Viet Nam

*E-mail: phanktcn@gmail.com or nguyenhuuphan@haui.edu.vn https://doi.org/10.36897/jme/145490
} 


\section{INTRODUTION}

The tool wear rate depends on properties of tool electrode (melting point, boiling point, thermal conductivity) and its highly influence the machining performance in the case of micro and macro EDM. Therefore, optimization of technological parameters in microEDM is very necessary, and this will lead to easier application of these electrodes in practice. Compared with the results of the single-objective optimization problem, the multiobjective problem will bring greater practical significance. Many methods have been used in this field, however the machining mechanism of micro-EDM is still not clearly understood. In addition, the number of technological parameters and the level of technological parameters is large, so choosing the right optimization techniques is extremely important. It will contribute to the improvement of the productivity and quality of the micro-EDM process, which leads to a reduction in the cost of the process.

The number of technical solutions used to optimize technological parameters in EDM and micro-EDM is quite large, and the optimal results of each different method are different. MRR, EWR and OC in micro-EDM were selected in multi-objective optimization using RSM [1]. The optimal results have high accuracy, the errors of MRR, EWR and OC are the largest by $\pm 8 \%, \pm 4.21 \%$ and $\pm 6.3 \%$, respectively. The influence of technological parameters on each quality criterion has been shown. SR, TWR, MRR, OC, TA and Circularity in micro-EDM for Ni-Ti were decided simultaneously using MOGA-II [2]. The quality parameters have been significantly improved at optimal conditions, but this calculation technique is quite complicated. The accuracy of multi-objective optimization results in EDM for 316L steel using NSGA-II is good ( $\max$ error $=10 \%$ ) [3]. The surface analysis by SEM, EDX of the surface after EDM machining showed that the surface is a collection of craters, microcracks and adhesion particles. The RSM multi-objective optimization model of EDM for $\mathrm{Ck} 45$ steel has been determined [4]. The accuracy of this model is quite high, and the maximum deviation of the model is approximately $7.2 \%$. However, using this solution leads to a large number of experiments, and this causes an increase in the cost of the study. The combined technique of RSM and Matlab was used to decide simultaneously MRR, SR and HV in WEDM [5]. This solution has high accuracy, but the computational technique is very complicated. Taguchi - GRA is used to solve multiobjective optimization problem in EDM [6]. The optimal result is determined by the ranking method, and the maximum error of the optimal result is equal to $8.88 \%$. and the ranking method is also introduced in many research results using GRA [7-9]. The popularity of application optimization techniques in solving multi-objective problems in machining methods has been shown [10] as per GRA technique which is the most popular method. The complexity of Taguchi and the combination of Taguchi with other methods in solving multi-objective optimization problems in EDM have been introduced [11-13]. Taguchi Utility Function Approach is a simple optimization technique, and it is applied to multiobjective decision in EDM for inconel 625 [14]. MRR and TWR have good results, however the weights of the quality indicators are determined experimentally, and thus the scope of the practical significance of the problem is reduced. Seven quality indicators in micro-EDM were simultaneously decided by the TOPSIS method [15]. The results show that TOPSIS is a simple and efficient computational technique. However, the weight value 
is also determined experimentally, and the optimal value is determined by the index ranking method. By the above optimization technique, MRR, SR and TWR in EDM were decided simultaneously, and the optimal efficiency was improved $\approx 14.2 \%$ [16] and the surface quality at optimal conditions has been significantly improved.

$\mathrm{S} / \mathrm{N}$ analysis was used to find the value of the optimal parameter set in EDM using MOORA-PCA [17]. The results show that the quality indicators determined by this method can be improved higher than it is by the ranking method. Compared with Taguchi - PCA Utility, the multi-objective optimization results in EDM by Taguchi - CRITIC - Utility are better [18] and the $\mathrm{S} / \mathrm{N}$ analysis will give the optimal efficiency is better. The $\mathrm{S} / \mathrm{N}$ analysis will provide better optimal efficiency. GA technique has been used for multi-objective optimization in EDM, and the obtained results are good [19]. However, the number of experiments is large, and the level of the technological parameters is constrained by the jump in the value of the survey level. And it can make it difficult to choose the level of technology parameters in EDM. The results of multi-objective optimization in EDM for inconel by Taguchi - Fuzzy are good [20]. However, the computational technique is very complex, and it makes it difficult to apply in practice. TOPSIS was used to simultaneously decide MRR, TWR, OC and TA in the micro-EDM for Ti-6Al-4V, and the results were significantly improved [21, 22]. The Fuzzy method used to determine the weights is very complex, and some important technological parameters in micro-EDM have not been explored such as RPM, C, etc. AHP-TOPSIS is a technically sound solution for multiobjective optimization in EDM for cobalt [23]. The results were compared with several other multi-objective optimization techniques, and TOPSIS was the most suitable solution. TOPSIS is a simple computational technique, and it is suitable for many fields of technology [24]. Compared to GRA, TOPSIS is the solution with higher optimal efficiency. Many optimal solutions have been proposed in EDM, but the number of studies in micro-EDM is small.

Existing literature review and concerned results, it has been shown that multi-target optimization research in micro-EDM is necessary. In this paper, the authors decided to simultaneously $\mathrm{Z}$ and $\mathrm{OC}$ in micro-EDM using Tungsten Carbide for Ti-6Al-4V using TOPSIS technique. The influence of technology parameters Voltage (V), Capacitance (C) and Spindle Rotation (RPM) on the quality parameters has been determined. The optimal result has been determined by $\mathrm{S} / \mathrm{N}$, and it is compared with the result using the ranking method. The machined surface quality at optimal conditions is also analyzed and evaluated by SEM images.

\section{MATERIALS AND DESIGN METHOLOGYS}

\subsection{EXPERIMENTAL SETUP}

The micro-EDM machine used in this study and its name is Hyper 10 Micro Electric Discharge Machining (Synergy nano systems). Tungsten Carbide (WC) was used as the micro electrode, and the size of the WC electrode diameter was $490 \mu \mathrm{m}$. The workpiece material was Ti-6Al-4V, and the elemental composition includes Ti (89.86\%), Al (5.89\%), 
$\mathrm{V}(3.93 \%), \mathrm{Fe}(0.165 \%), \mathrm{O}(0.128 \%), \mathrm{C}(0.017 \%), \mathrm{N}(0.005 \%)$ and $\mathrm{H}(0.002 \%)$. The dielectric fluid was EDM Oil, voltage (V), capacitance (C) and spindle rotation speed (RPM) were the investi-gated technology parameters, and the levels of the technology parameters are as shown in Table 1. Experimental design by Taguchi method was used in this study. Based on the number of technological parameters and their levels will determine the experimental matrix. Three input process parameters and three levels in the study, L9 orthogonal array was selected as the experimental matrix, Table 2 . The experimental results of $\mathrm{Z}$ and $\mathrm{OC}$ are shown in Fig. 1 and Table 2. The process parameters are adjusted directly on the experimental machine (Hyper 10 Micro EDM). Z Co-Ordinate was reading shown by machine on screen related to depth of the electrode in the drilled hole cavity, and the OC is determined through the image analyzer.

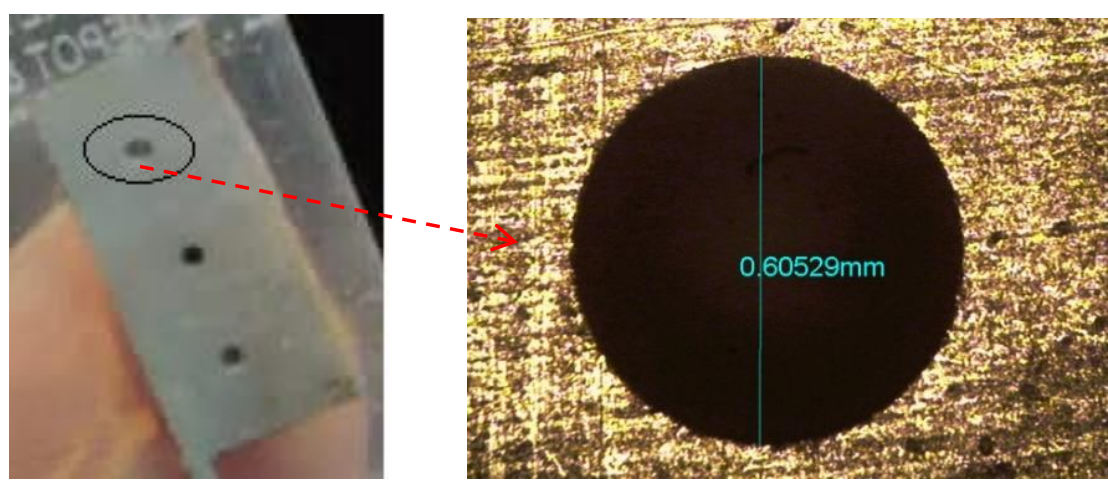

Fig. 1. Experimental sample

Table 1. Process parameters and their levels for final experiments

\begin{tabular}{|c|c|c|c|}
\hline \multirow{2}{*}{ Process Parameters } & \multicolumn{3}{|c|}{ Levels } \\
\cline { 2 - 4 } & 1 & 2 & 3 \\
\hline Voltage (V) & 120 & 140 & 160 \\
\hline Capacitance & $100 \mathrm{pF}$ & $1000 \mathrm{pF}$ & $10 \mathrm{nF}$ \\
\hline Spindle Rotation (RPM) & 200 & 400 & 600 \\
\hline
\end{tabular}

Table 2. Experimental Results with Carbide Tungsten Micro Electrode

\begin{tabular}{|c|c|c|c|c|c|}
\hline \multirow{2}{*}{$\begin{array}{c}\text { Expt. } \\
\text { No. }\end{array}$} & \multicolumn{3}{|c|}{ Process parameters } & \multicolumn{2}{c|}{ Response variables } \\
\cline { 2 - 6 } & $\begin{array}{c}\text { Voltage } \\
(\mathrm{V})\end{array}$ & Capacitance (F) & RPM & $\begin{array}{c}\mathrm{Z} \\
(\mathrm{mm})\end{array}$ & $\begin{array}{c}\text { OC } \\
(\mu \mathrm{m})\end{array}$ \\
\hline 1 & 120 & $100 \mathrm{pF}$ & 200 & 0.59 & 102.57 \\
\hline 2 & 120 & $1000 \mathrm{pF}$ & 400 & 1.16 & 83.94 \\
\hline 3 & 120 & $10 \mathrm{nF}$ & 600 & 1.15 & 92.66 \\
\hline 4 & 140 & $100 \mathrm{pF}$ & 400 & 0.71 & 99.45 \\
\hline 5 & 140 & $1000 \mathrm{pF}$ & 600 & 0.9 & 90.02 \\
\hline 6 & 140 & $10 \mathrm{nF}$ & 200 & 1.31 & 80.55 \\
\hline 7 & 160 & $100 \mathrm{pF}$ & 600 & 0.62 & 96.58 \\
\hline 8 & 160 & $1000 \mathrm{pF}$ & 200 & 1.17 & 90.68 \\
\hline 9 & 160 & $10 \mathrm{nF}$ & 400 & 1.84 & 93.59 \\
\hline
\end{tabular}




\subsection{METHODOLOGY}

In $\mu$-EDM, the work to repair the defects of the product after machining by this method is very difficult and its cost is very expensive. And the surfaces after $\mu$-EDM will often be used in practice without going through finishing. Therefore, Optimization of technological parameters in $\mu$-EDM is very necessary, and especially for multi-objective decisions in this field [25]. Many multi-objective decision techniques have been used in this field, however the TOPSIS method is very commonly used in EDM and $\mu$-EDM. In this study, Taguchi, AHP and TOPSIS techniques are combined to solve the problem, and the multi-objective decision by TOPSIS is made according to the diagram in Fig. 2 [26].

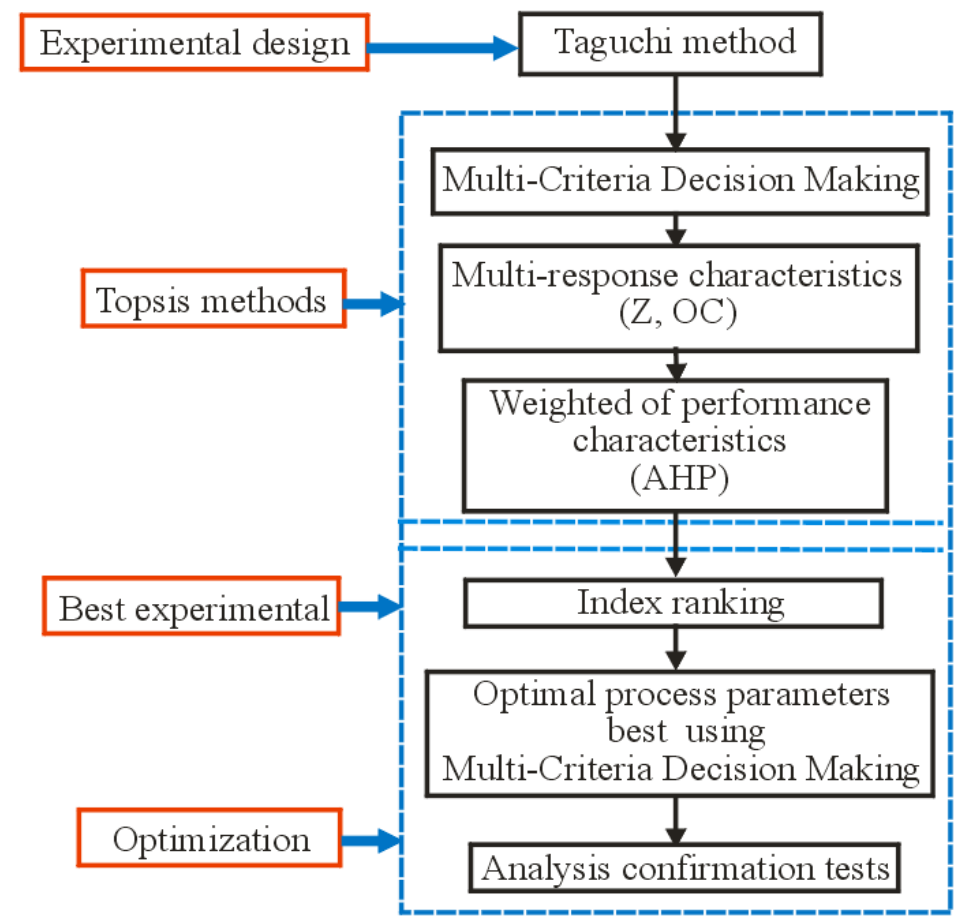

Fig. 2. Diagram of multi-criteria decision making using Taguchi - AHP- TOPSIS [27]

The Analytic Hierarchy Process (AHP) is a commonly used method to calculate the value of weights in multi-objective optimization problems. Because the calculation process by this method is quite simple, concise and its results have suitable practical significance. $S / N$ ratio analysis was performed according to (1), (2) and (3):

Smaller is better: $S / N=-10 \log _{10}[S]$

$$
\mathrm{S}=\frac{\mathrm{y}_{1}^{2}+\mathrm{y}_{2}^{2}+\ldots+\mathrm{y}_{\mathrm{n}}^{2}}{\mathrm{n}}
$$

$\mathrm{S}-$ The average squares of the measured values.

$\mathrm{y}_{\mathrm{i}}-$ Value received by experiment $(\mathrm{i}=1 \div \mathrm{n})$.

$\mathrm{n}-$ The number of experiments. 
Larger is better: $S / N=-10 \log _{10}[\mathrm{~L}]$

$$
\mathrm{L}=\frac{\frac{1}{\mathrm{y}_{1}^{2}}+\frac{1}{\mathrm{y}_{2}^{2}}+\ldots+\frac{1}{\mathrm{y}_{\mathrm{n}}^{2}}}{\mathrm{n}}
$$

$\mathrm{L}$ - The average squared inverse of the measured values.

Nominal value is the best: $S / N=-10 \log _{10}[N]$

$$
\mathrm{N}=\frac{\left(\mathrm{y}_{1}-\mathrm{m}\right)^{2}+\left(\mathrm{y}_{2}-\mathrm{m}\right)^{2}+\ldots+\left(\mathrm{y}_{\mathrm{n}}-\mathrm{m}\right)^{2}}{\mathrm{n}}
$$

$\mathrm{m}-$ value targets.

\section{RESULTS AND DISCUSSION}

\subsection{EFFECT OF PROCESS PARAMETERS ON Z AND OC}

Effect of process parameters on $\mathbf{Z}$ : The influence of the process parameters on $\mathrm{Z}$ is shown in Fig. 3. The results showed that the increase of $\mathrm{V}=120 \mathrm{~V}$ to $140 \mathrm{~V}$ led to a negligible increase in $\mathrm{Z}$, and the increase in $\mathrm{Z}$ is $0.6 \%$ (Fig. 3a). This is because the pulse energy is not significantly changed in this range of $\mathrm{V}$. However, $\mathrm{V}=140 \mathrm{~V}-160 \mathrm{~V}$, it resulted in $\mathrm{Z}$ being increased quite strongly, and the increase in $\mathrm{Z}$ is $24.3 \%$. This may be due to the fact that the spark energy and the size of the discharge gap are significantly increased. This has led to an increase in the amount of material of the workpiece being melted and evaporated. Chips are moved out of the discharge gap more easily, and the machining process is more stable. The change in $\mathrm{C}$ will affect the energy and discharge frequency of the sparks in the micro-EDM. So $\mathrm{C}=100 \mathrm{pF}-10 \mathrm{nF}$, it led to a very strong increase in $\mathrm{Z}$, and the increase in $\mathrm{Z}$ is $123.95 \%$ (Fig. 3b).

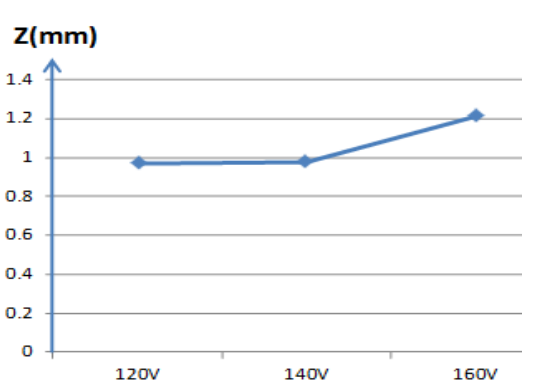

a) Effect of V

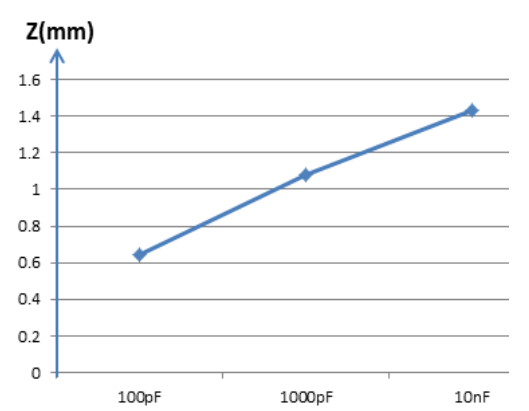

b) Effect of C

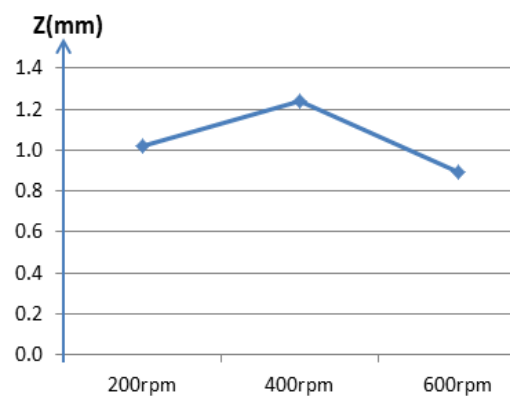

c) Effect of RPM

Fig. 3. Effect of V, C and RPM on Z

The reason could be that the increase of $\mathrm{C}$ led to an increase in the spark energy and the number of sparks in one pulse. RPM is an important technological parameter in microEDM, because a change in RPM has a direct effect on the removal of chip particles from the gap between the electrode and the workpiece. And it will affect the stability of the 
machining process. Compared to $\mathrm{Z}$ at $\mathrm{RPM}=400 \mathrm{rpm}, \mathrm{Z}$ at $\mathrm{RPM}=200 \mathrm{rpm}$ and $\mathrm{RPM}=$ $600 \mathrm{rpm}$ have been significantly reduced, the reduction of $\mathrm{Z}$ by $17.25 \%$ and $38.95 \%$, respectively (Fig. 3c). The reason may be that the value of RPM is small, it will lead to the ejection effect of the dielectric solution and the chip leaving the discharge gap is negligible. On the other hand, the RPM is too large, it also leads to the chip particles moving around in the discharge gap. This causes the stability of the machining process to be reduced and arcing and short circuits will occur more often.

Effect of process parameters on OC: The value of OC will affect the machining accuracy in the micro-EDM, and an increase of the OC will lead to a decrease in the machining accuracy. The increase of V, C and RPM, which led to a significant increase in the value of OC (Fig. 4). Compared to $\mathrm{V}=120 \mathrm{~V}$, the OCs at $\mathrm{V}=140 \mathrm{~V}$ and $160 \mathrm{~V}$ are increased by $2.42 \%, 8.44 \%$, respectively (Fig. 4a). The cause may be due to the increase of pulse energy as $\mathrm{V}$ is increased. The effect of $\mathrm{C}$ is similar to that of $\mathrm{V}$. Compared to $\mathrm{C}=$ $100 \mathrm{pF}$, the $\mathrm{OC}$ at $\mathrm{C}=1000 \mathrm{pF}$ is increased by $4.04 \%$, it is by $8.28 \%$ at $\mathrm{C}=10 \mathrm{nF}$ (Fig. 4b). Because the electrical energy during charging and discharging is greatly improved, the amount of workpiece material to be melted and evaporated is increased accordingly. The increase of RPM, it has led to OC is increased accordingly, and OC is the largest at $\mathrm{RPM}=600 \mathrm{rpm}$ and it is the smallest at RPM $=200 \mathrm{rpm}$ (Fig. 4c). The reason could be that the RPM was too high which led to the fault discharge bridge formed by the chip particles, and it led to the increase in the value of OC. And the small RPM will result in reduced machining efficiency due to the influence of the dielectric solution and the chip particles existing in the discharge gap. Compared to RPM $=200 \mathrm{rpm}$, the $\mathrm{OC}$ at $400 \mathrm{rpm}$ and $600 \mathrm{rpm}$ is increased by $1.04 \%$ and $1.49 \%$, respectively.

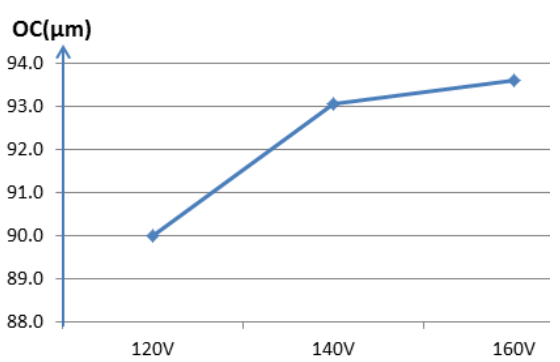

a) Effect of V

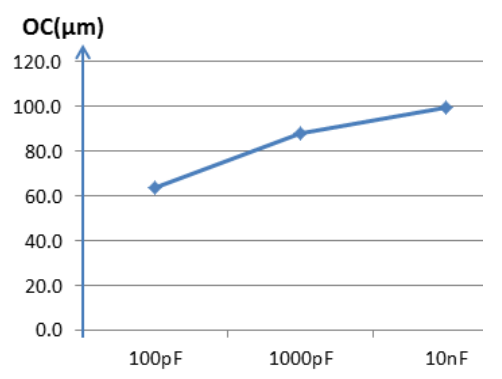

b) Effect of C

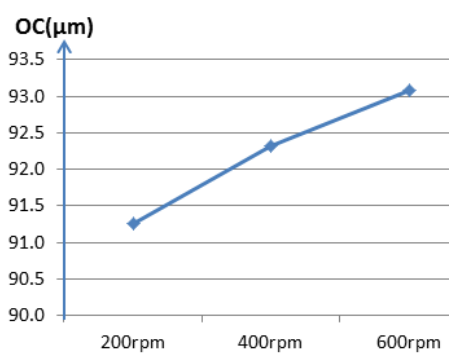

c) Effect of RPM

Fig. 4. Effect of V, C and RPM on OC

\subsection{MULTI OBJECTIVE OPTIMIZATION USING TOPSIS}

Calculation in TOPSIS method

Step 1: Matrix of quality indicators in micro-EDM

Step 2: Normalize the matrix: The results are shown in Table 3.

$$
\mathrm{X}=\left[\begin{array}{ll}
Z_{1} & O C_{1} \\
Z_{2} & O C_{2} \\
\cdot & \cdot \\
\cdot & \cdot \\
\cdot & \cdot \\
Z_{9} & O C_{9}
\end{array}\right]
$$


Step 3: Weight of quality indicators by AHP: The weighted value of the quality criteria will determine the practical significance of the optimal result. Compared to OC, $\mathrm{Z}$ in microEDM is preferred. The values of the weights of $\mathrm{Z}$ and $\mathrm{OC}$ as $\mathrm{W}_{\mathrm{Z}}=0.673$ and $\mathrm{W}_{\mathrm{OC}}=0.327$, respectively. Assign weights to the quality indicator matrix, and the results are shown in Table 5.

Table 3. Normalized data

\begin{tabular}{|c|c|c|c|c|c|}
\hline \multirow{2}{*}{$\begin{array}{c}\text { Exp. } \\
\text { No }\end{array}$} & \multirow{2}{*}{$\begin{array}{c}\text { Voltage } \\
(\mathrm{V})\end{array}$} & Capacitance & \multirow{2}{*}{ RPM } & \multicolumn{2}{|c|}{ Vector normalization } \\
\cline { 4 - 6 } & & & & $\mathrm{X}_{\mathrm{Z}}$ & $\mathrm{X}_{\mathrm{OC}}$ \\
\hline 1 & 120 & $100 \mathrm{pF}$ & 200 & 0.1764 & 0.3698 \\
\hline 2 & 120 & $1000 \mathrm{pF}$ & 400 & 0.3468 & 0.3026 \\
\hline 3 & 120 & $10 \mathrm{nF}$ & 600 & 0.3439 & 0.3340 \\
\hline 4 & 140 & $100 \mathrm{pF}$ & 400 & 0.2123 & 0.3585 \\
\hline 5 & 140 & $1000 \mathrm{pF}$ & 600 & 0.2691 & 0.3245 \\
\hline 6 & 140 & $10 \mathrm{nF}$ & 200 & 0.3917 & 0.2904 \\
\hline 7 & 160 & $100 \mathrm{pF}$ & 600 & 0.1854 & 0.3482 \\
\hline 8 & 160 & $1000 \mathrm{pF}$ & 200 & 0.3498 & 0.3269 \\
\hline 9 & 160 & $10 \mathrm{nF}$ & 400 & 0.5502 & 0.3374 \\
\hline
\end{tabular}

Step 4: Determine the best solution $\left(\mathrm{A}^{+}\right)$and the worst solution $\left(\mathrm{A}^{-}\right)$: Values are shown in Table 4.

Table 4. Positive ideal solution and negative ideal solution

\begin{tabular}{|c|c|c|}
\hline Criteria & $\mathrm{Z}$ & OC \\
\hline $\mathrm{A}+$ & 0.370 & 0.095 \\
\hline $\mathrm{A}-$ & 0.119 & 0.121 \\
\hline
\end{tabular}

Step 5: Determine $\mathrm{S}_{\mathrm{i}}^{+}$and $\mathrm{S}_{\mathrm{i}}^{-}$: These results in Table 5.

Table 5. TOPSIS values using vector normalization and $\mathrm{S} / \mathrm{N}$ ratio values

\begin{tabular}{|c|c|c|c|c|c|c|c|c|c|c|c|}
\hline $\begin{array}{c}\text { Exp. } \\
\text { No }\end{array}$ & $\mathrm{y}^{\prime} \mathrm{z}$ & $\mathrm{y}^{\prime} \mathrm{OC}$ & $\mathrm{y}^{+} \mathrm{z}$ & $\mathrm{y}^{+} \mathrm{OC}$ & $\mathrm{y}^{-} \mathrm{z}$ & $\mathrm{y}^{-} \mathrm{oC}$ & $\mathrm{S}_{\mathrm{i}}^{+}$ & $\mathrm{S}_{\mathrm{i}}^{-}$ & $\mathrm{C}_{\mathrm{i}}^{*}$ & Ranking & S/N ratio \\
\hline 1 & 0.119 & 0.121 & -0.252 & 0.026 & 0.000 & 0.000 & 0.2530 & 0.0000 & 0.000 & 9 & -21.8303 \\
\hline 2 & 0.234 & 0.099 & -0.137 & 0.004 & 0.115 & 0.022 & 0.1370 & 0.1168 & 0.460 & 4 & -6.6137 \\
\hline 3 & 0.232 & 0.109 & -0.139 & 0.014 & 0.113 & 0.012 & 0.1397 & 0.1133 & 0.448 & 5 & -6.8780 \\
\hline 4 & 0.143 & 0.117 & -0.228 & 0.022 & 0.024 & 0.004 & 0.2286 & 0.0244 & 0.097 & 7 & -16.4205 \\
\hline 5 & 0.181 & 0.106 & -0.189 & 0.011 & 0.062 & 0.015 & 0.1896 & 0.0641 & 0.253 & 6 & -12.0412 \\
\hline 6 & 0.264 & 0.095 & -0.107 & 0.000 & 0.145 & 0.026 & 0.1067 & 0.1473 & 0.580 & 2 & -4.7314 \\
\hline 7 & 0.125 & 0.114 & -0.246 & 0.019 & 0.006 & 0.007 & 0.2464 & 0.0093 & 0.036 & 8 & -19.2515 \\
\hline 8 & 0.236 & 0.107 & -0.135 & 0.012 & 0.117 & 0.014 & 0.1354 & 0.1176 & 0.465 & 3 & -6.6137 \\
\hline 9 & 0.370 & 0.110 & 0.000 & 0.015 & 0.252 & 0.011 & 0.0154 & 0.2519 & 0.942 & 1 & -1.1499 \\
\hline
\end{tabular}

Step 6: Determine the ideal solution $\left(\mathrm{C}^{*}\right)$. These results in Table 5. $\mathrm{C}^{*}$ as the largest will correspond to the most ideal solution. 
Step 7: Ranking and selecting the best solution, Table 5. The best solution is the one with a ranking of $1^{\text {st }}$.

*The best experiment: The analysis results show that ranking of $\mathrm{C}^{*}$ at Exp.09 is ranked $1^{\text {st }}$, and parameter process are $\mathrm{V}=160 \mathrm{~V}, \mathrm{C}=10 \mathrm{nF}$ and $\mathrm{RPM}=400 \mathrm{rpm}$. Values of the quality criterias at this condition include $\mathrm{Z}=1.84 \mathrm{~mm}$ and $\mathrm{OC}=93.94 \mu \mathrm{m}$.

\subsection{SURFACE QUALITY ANALYSIS}

The quality of the machined surface is a very important factor in $\mu$-EDM, because its results will directly affect the workability of the product after processing. Experimental results in the $\mu$-EDM using WC electrode at dark conditions were compared with the results of the first experiment. Figure 5 has shown that the number of particles adhering to the machined surface at optimal conditions is less than that of Exp.01. The reason may be that the chip escape process at optimal conditions is better. This result will contribute to improving the roughness of the machined surface [28]. Compared with the results at Exp.01, the size and number of microcracks appearing on the machined surface at optimal conditions are smaller, Figure 6. It will contribute to improving the durability of the workpiece surface after $\mu$-EDM. The number of particles adhering to the machined surface on the machined surface is also less, and The smoothness of the machined surface is significantly improved (Fig. 5). These results showed that the surface quality at optimal conditions in $\mu$-EDM was also significantly improved. This has contributed to increasing the practical significance of the optimal results [29].

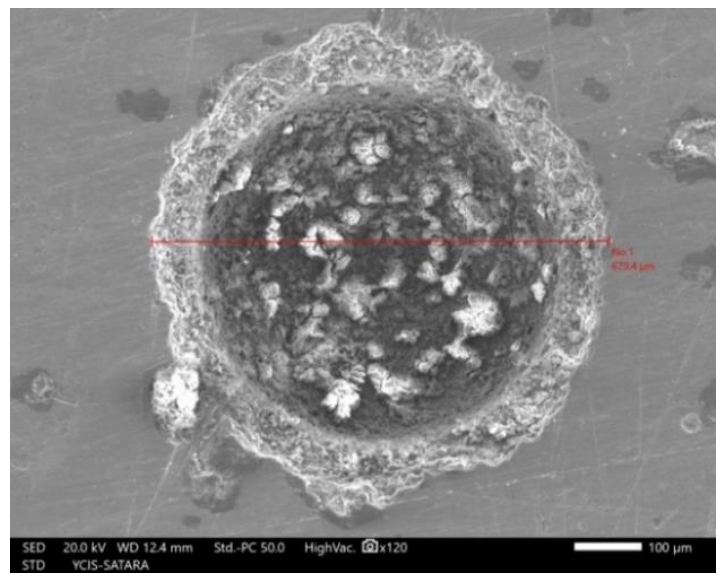

a) Exp. 01

$(\mathrm{V}=120 \mathrm{~V}, \mathrm{C}=100 \mathrm{pF}, \mathrm{RPM}=200 \mathrm{rpm})$

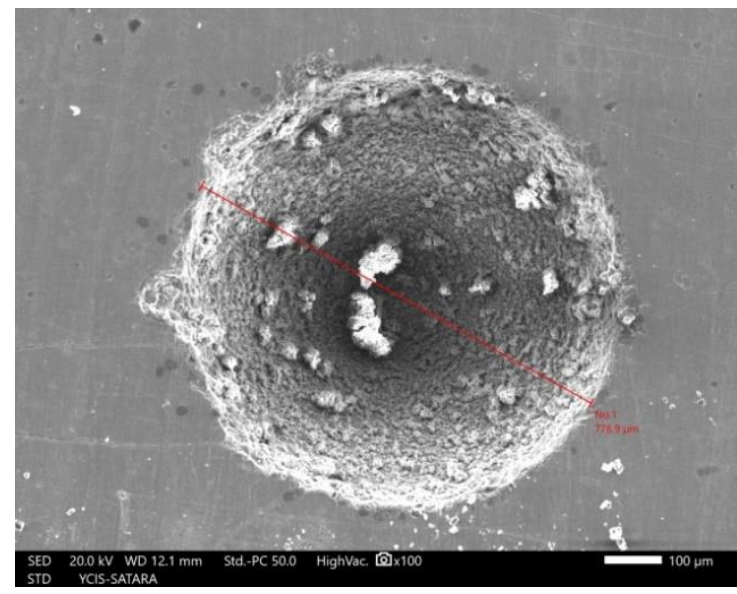

b) Optimal process

Fig. 5. SEM of micro- hole in $\mu$-EDM at optimization process

Compared with the EDX results of the workpiece shown in Figs.7 and 8, the EDX results of the machined surface after micro-EDM showed that the percentage of $\mathrm{Ti}$ and $\mathrm{Al}$ is significantly reduced, $\mathrm{V}$ is not present on the machined surface layer, and instead the appearance of $\mathrm{C}$ and $\mathrm{O}$ elements on the machined surface. However, we did not find the appearance of $\mathrm{W}$ on the machined surface, and this indicates that the wear of the 
electrode is very small. The percentage of $\mathrm{C}$ and $\mathrm{O}$ present in the machined surface layer is very large, which can be attributed to the $\mathrm{C}$ generated by the cracking of the oil dielectric solution and a very small part from the WC electrode, and $\% \mathrm{O}$ is produced by $\mathrm{O}$ as impurities in the WC electrode material [25] and air bubbles exist in the discharge gap. The cause of the reduction of $\mathrm{V}, \mathrm{Ti}$ and $\mathrm{Al}$ on the machined surface layer can be because $\mathrm{C}$ and $\mathrm{O}$ have replaced the positions of these elements in the machined surface layer. Changes in the elemental composition of the surface layer can change the workability of the machined surface layer.

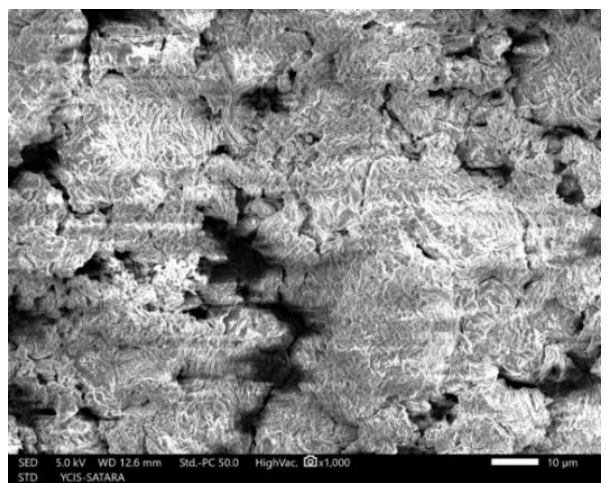

a) Exp. 01

$(\mathrm{V}=120 \mathrm{~V}, \mathrm{C}=100 \mathrm{pF}, \mathrm{RPM}=200 \mathrm{rpm})$

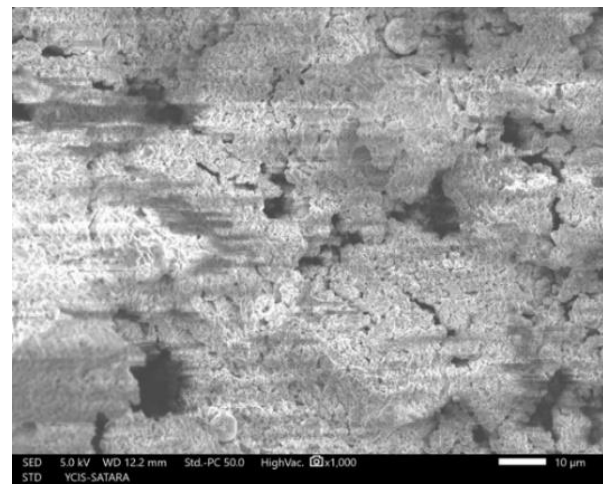

b) Optimal process

Fig. 6. Micro-cracks on machined surface in $\mu$-EDM

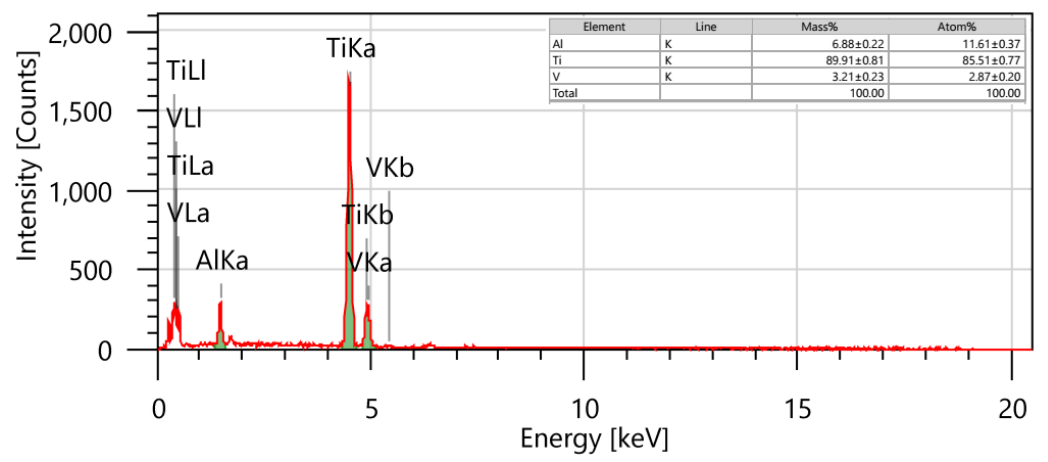

Figure 7. SEM- EDX of Ti-6Al-4V workpiece

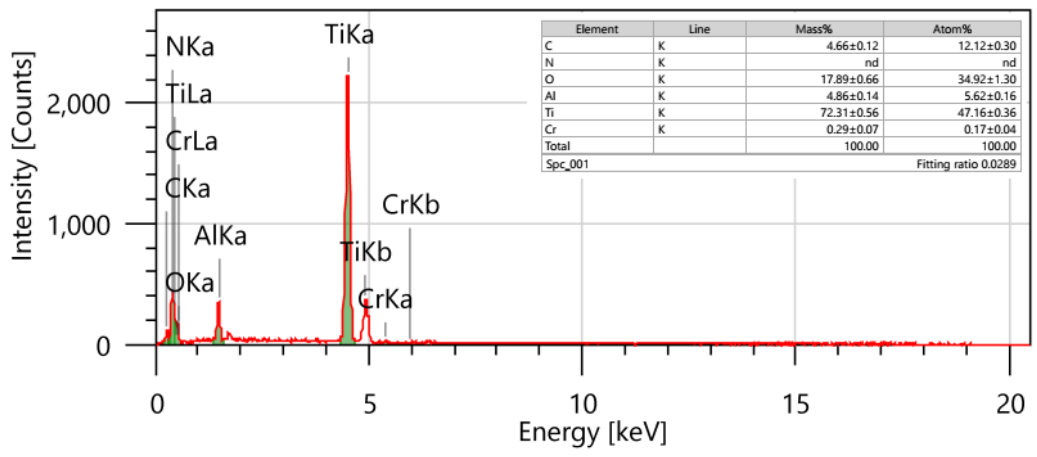

Fig. 8. SEM- EDX of machined surface after micro-EDM with WC electrode 


\section{CONCLUSIONS}

The study decided to multi-target in micro-EDM using Tungsten Carbide (WC) for Ti-6Al-4V. The results of the study helped us to draw the following conclusions:

Voltage (V), capacitance (C) and electrode rotation speed (RPM) had a significant influence on machining productivity and machining accuracy, and the increase of the parameters has led to an increase in $\mathrm{Z}$ and OC. The influence of technology parameters on OC is stronger than it's influence on Z. C and RPM is stronger than it's effect on V.

The ranking optimization results have been shown that $9^{\text {th }}$ Exp. in the experiment matrix is the best. The optimal set of technological parameters includes $\mathrm{V}=160 \mathrm{~V}, \mathrm{C}=$ $10 \mathrm{nF}$ and $\mathrm{RPM}=400 \mathrm{rpm}$, and the values of the quality indicators include $\mathrm{Z}=1.84 \mathrm{~mm}$ and $\mathrm{OC}=93.94 \mu \mathrm{m}$.

Machined surface after micro-EDM at optimal conditions have been significantly improved. However, the changes in the elemental composition of the surface layer have led to changes in the physico-chemical properties of this layer, and it is necessary to have studies on its workability such as abrasion, corrosion, mechanical strength, etc.

TOPSIS combined with Taguchi has created a multi-objective optimization solution, its calculation method is simple, and the implementation steps are concise. Therefore, it can be an effective solution in multi-objective decision in micro-EDM, and it can also be suitable for many other machining technologies. Even so, it is necessary to compare the results of this method with the results of some other new and modern solutions.

\section{REFERENCES}

[1] RAMASWAMY A., PERUMAL A.V., 2020, Multi-Objective Optimization of Drilling EDM Process Parameters of LM13 Al Alloy-10ZrB2-5TiC Hybrid Composite Using RSM, J. Braz. Soc. Mech. Sci. Eng., 42, 432, https://doi.org/10.1007/s40430-020-02518-9

[2] ABIDI M.H., AL-AHMARIA A.M., UMER U., RASHEED M.S., 2018, Multi-Objective Optimization of MicroElectrical Discharge Machining of Nickel-Titanium-Based Shape Memory Alloy Using MOGA-II, Measurement, $125,336-349$.

[3] AL-AMIN M., ABDUL-RANI A.M., AHMED R., RAO T.V.V.L.N., 2021, Multiple-Objective Optimization of Hydroxyapatite-Added EDM Technique for Processing of 316L-Steel, Materials and Manufacturing Processes, 36/10, 1134-1145, https://doi.org/10.1080/10426914.2021.1885715.

[4] EL-TAWEEL T.A., 2009, Multi-Response Optimization of EDM with Al-Cu-Si-TiC P/M Composite Electrode, Int. J. Adv. Manuf. Technol., 44, 100-113, https://doi.org/10.1007/s00170-008-1825-6.

[5] CHAUDHARI R., VORA J.J., MANI PRABU S.S., et al., 2019, Multi-Response Optimization of WEDM Process Parameters for Machining of Superelastic Nitinol Shape-Memory Alloy Using a Heat-Transfer Search Algorithm, Materials, 12/8, 1277, https://doi.org/10.3390/ma12081277.

[6] KHANNA R., KUMAR A., GARG M.P., et al. 2015, Multiple Performance Characteristics Optimization for Al 7075 on Electric Discharge Drilling by Taguchi Grey Relational Theory, J. Ind. Eng. Int. 11, 459-472, https:// doi.org/10.1007/s40092-015-0112-z.

[7] PAYAL H., MAHESHWARI S., BHARTI P.S., et al. 2019, Multi-Objective Optimisation of Electrical Discharge Machining for Inconel 825 Using Taguchi-Fuzzy Approach, Int. J. inf. tecnol., 11, 97-105, https://doi.org/10.1007/ s41870-018-0102-7.

[8] PRAGADISH N., PRADEEP KUMAR M., 2016, Optimization of Dry EDM Process Parameters Using Grey Relational Analysis, Arab. J. Sci. Eng., 41, 4383-4390, https://doi.org/10.1007/s13369-016-2130-6.

[9] TIEN L.B., HUU P.N, CUONG N., DUC T.N., 2018, Characteristics optimization of powder mixed electric discharge machining using titanium powder for die steel materials, Proceedings of the Institution of Mechanical Engineers, Part E: Journal of Process Mechanical Engineering, 232/3, 281-298. 
[10] KUMAR R., SINGH S., BILGA P.S., et al., 2021, Revealing the Benefits of Entropy Weights Method for MultiObjective Optimization in Machining Operations: A Critical Review, Journal of Materials Research and Technology, 10, 1471-1492.

[11] TAMANG S.K., NATARAJAN N., CHANDRASEKARAN M., 2017, Optimization of EDM Process in Machining Micro Holes for Improvement of Hole Quality, J. Braz. Soc. Mech. Sci. Eng., 39, 1277-1287, https:// doi.org/ 10.1007/s40430-016-0630-7.

[12] NGUYEN H.P., 2020, Multi-Objective Optimization in Titanium Powder Mixed Electrical Discharge Machining Process Parameters for Die Steels, Alexandria Engineering Journal, 59, 4063-4079, https://doi.org/10.1016/ j.aej.2020.07.012

[13] PORWAL R.K., YADAVA V., RAMKUMAR J., 2012, Artificial Neural Network Modelling and Multi Objective Optimisation of Hole Drilling Electro Discharge Micro Machining of Invar, Int. J. Mechatronics and Manufacturing Systems, 5, 5/6, 470-494.

[14] SAHOOA S.K., THIRUPATHI N., SARASWATHAMMA K., 2020, Experimental Investigation and MultiObjective Optimization of Die sink EDM Process Parameters on Inconel-625 alloy by using Utility Function Approach, Materials Today: Proceedings, 24, 995-1005.

[15] MANIVANNAN R., KUMAR M.P., 2016, Multi-Response Optimization of Micro-EDM Process Parameters on AISI304 Steel Using TOPSIS, J. Mech. Sci. Technol., 30, 137-144, https://doi.org/10.1007/s12206-015-1217-4.

[16] RAJ S.O.N., PRABHU S., 2017, Analysis of Multi Objective Optimisation Using TOPSIS Method in EDM Process with CNT Infused Copper Electrode, Int. J. Machining and Machinability of Materials, V, 191, 76-94.

[17] MAJUMDER H., KALIPADA M., 2017, Optimization of Machining Condition in WEDM for Titanium Grade 6 Using MOORA Coupled with PCA - A Multivariate Hybrid Approach, Journal of Advanced Manufacturing Systems, 16/2, 81-99.

[18] CHANDRASHEKARAPPA M., KUMAR S.J., PIMENOV D.Y., GIASIN K., 2021, Experimental Analysis and Optimization of EDM Parameters on HcHcr Steel in Context with Different Electrodes and Dielectric Fluids Using Hybrid Taguchi-Based PCA-Utility and CRITIC-Utility Approaches, Metals, 11, 419, https://doi.org/10.3390/ met11030419.

[19] PADHI P.C., MAHAPATRA S.S., YADAV S.N., TRIPATHY D.K., 2016, Multi-Objective Optimization of Wire Electrical Discharge Machining (WEDM) Process Parameters Using Weighted Sum Genetic Algorithm Approach, Journal of Advanced Manufacturing Systems, 15/2, 85-100.

[20] PONAPPA K., ARAVINDAN S., RAO P.V., et al., 2010, The Effect of Process Parameters on Machining of Magnesium Nano Alumina Composites Through EDM, Int. J. Adv. Manuf. Technol., 46, 1035-1042, https://doi.org /10.1007/s00170-009-2158-9.

[21] TIWARY A.P., PRADHAN B.B., BHATTACHARYYA B., 2014, Application of Multi-Criteria Decision Making Methods for Selection of Micro-EDM Process Parameters, Adv. Manuf., 2, 251-258 https://doi.org/10.1007/ s40436-013-0050-1.

[22] NADDA R., KUMAR R., SINGH T., CHAUHAN R., PATNAIK A., GANGIL B., 2018, Experimental Investigation and Optimization of Cobalt Bonded Tungsten Carbide Composite by Hybrid AHP-TOPSIS Approach, Alexandria Engineering Journal, 57/4, 3419-3428.

[23] SHUKLA A., AGARWAL P., RANA R.S., PUROHIT R., 2017, Applications of TOPSIS Algorithm on Various Manufacturing Processes: A Review, Materials Today, Proceedings, 4, 5320-5329.

[24] TOWHIDUL ISLAM NAYIM S.M, HASAN M.Z., JAMWAL A., THAKUR S., GUPTA S., 2019, Recent Trends \& Developments in Optimization and modelling of Electro-discharge Machining Using Modern Techniques: A Review, AIP Conference Proceedings, 2148/1, https://doi.org/10.1063/1.5123973.

[25] NGUYEN P.H., MUTHURAMALINGAM T., 2021, Multi-Criteria Decision-Making of Vibration-Aided Machining for High Silicon-Carbon Tool Steel with Taguchi-TOPSIS Approach, Silicon, 13/8, 2771-2783.

[26] NGUYEN H.P., PHAM V.D. NGO N.V., 2018, Application of TOPSIS to Taguchi Method for Multicharacteristic Optimization of Electrical Discharge Machining with Titanium Powder Mixed into Dielectric Fluid, Int. J. Adv. Manuf. Technol., 98, 1179-1198.

[27] MUTHURAMALINGAM T., RAMAMURTHY A., SRIDHARAN K., ASHWIN S., 2018, Analysis of Surface Performance Measures on WEDM Processed Titanium Alloy with Coated Electrodes, Materials Research Express, 5/12, 126503.

[28] MUTHURAMALINGAM T., 2019, Measuring the Influence of Discharge Energy on White Layer Thickness in Electrical Discharge Machining Process, Measurement, 131, 694-700.

[29] PAUL T., SEMONES V.M. BEDEKAR D.G.B, BATZER S.A., 2004, Tool/Workpiece Chemical Transfer on Standard WC-Co Tool Inserts in Turning on Ti-6A1-4V, Journal of the Mechanical Behavior of Materials, 15, $1-12$. 